US joins Soviet venture

\section{Washington}

A convergence of chance events, including the death of physicist Andrei Sakharov and a Soviet decision to adopt international radio frequencies for its space projects, has led to a new US-Soviet cooperative space venture.

Earlier this month, US Vice President Dan Quayle announced that the United States would provide ground-based hardware and services for a Soviet radiotelescope to be launched in the mid-1990s. In a joint appearance in Washington, Quayle and Yri Dubinin, the Soviet ambassador, applauded the venture as a "significant step" towards new cooperation.

Known as RADIOASTRON, the 10-metre orbiting Soviet telescope will work with ground-based radiotelescopes to form a very-long-baseline interferometry (VLBI) network of unprecedented size. Present VLBI networks are restricted by the Earth's diameter to several thousand miles, but with one element in Earth orbit, the baseline can be expanded by an order of magnitude. The RADIOASTRON network, like other VLBI networks, will be used to make highresolution maps of distant galaxies, quasars and pulsars.

One of the last letters signed by Sakharov before his death was an appeal to the United States to collaborate in the Soviet venture. Although officials at the National Aeronautics and Space Administration (NASA) and Soviet officials have discussing joint participation in ANIMAL RESEARCH

\section{Monkey imports may be curtailed in US}

\section{Washington}

IN the wake of the discovery last year that monkeys in two US laboratories are carrying the deadly Ebola virus, health officials are considering banning imports of the main species of research primates.

In a letter to about 200 primate importers, William Roper, director of the US Centers for Disease Control (CDC) warned that "active transmission [of Ebola-like virus] in monkeys in quarantine has been demonstrated. The health of your workers may be at risk." Antibodies to the virus have recently shown up in the blood of two US laboratory workers.

CDC are considering temporary restrictions on the importation of cynomolgus monkeys, which make up 75 per cent of all primates imported to the United States. Although about 16,000 cynomolgus monkeys were imported last year, many large primate centres also breed their own and should be able to weather temporary import restrictions.

G. Christopher Anderson
RADIOASTRON for three years, talks had started on equipment compatibility and export controls, says Samuel Keller, NASA assistant deputy administrator.

But in recent months the US National Radio Astronomy Observatory has at last received permission to export four special data recorders built for the Soviet mission, RADIOASTRON planners agreed to switch to communications frequencies that are compatible with US and international facilities, and Sakharov's stepson returned from the Nobel laureate's funeral to deliver the posthumous appeal to NASA administrator Richard Truly. The convergence of events adds "a special note of poignancy" to the cooperative venture, Quayle said.

In addition to the data recorders, which are on extended loan, NASA will provide data-processing services and will track RADIOASTRON with its Deep Space
Network, which is an order of magnitude more accurate than Soviet networks, according to Keller. The additional worldwide tracking will allow RADIOASTRON to make useful observations 90 per cent of the time, more than twice what it can do with Soviet tracking alone. The total cost to the United States is expected to be $\$ 20$ million over five or six years.

The Soviets are building a groundbased 70-metre radiotelescope in Uzbekistan to support the RADIOASTRON project. Known as the Suffa telescope, the new facility will join two existing Soviet 70-metre radiotelescopes in the Crimea and the Far East.

A group of 70 scientists from 15 countries is additionally planning a 25 -metre space radiotelescope known as the International VLBI Satellite (IVS). The IVS is "a natural next step" to the RADIOASTRON mission, wrote Sakharov, adding that "we hope that NASA will support this mission also".

G. Christopher Anderson

\title{
SPACE SCIENCE
}

\section{Financial hiatus for Hipparcos satellite}

\section{London}

THE European Space Agency (ESA) council this week debates future budgetary increases for the Horizon 2000 space science programme, following the presentation of a report on Horizon 2000's management and troubled finances. The programme, set up in 1984, has been plagued by Britain's reluctance to increase contributions in line with its partners - a major problem, as Horizon 2000's budget must be agreed unanimously by the 13 subscriber states. After a year of negotiation, Britain agreed the last Horizon 2000 budget increase in December 1988 only when ESA commissioned a review of the programme.

The review team, chaired by Professor Klaus Pinkau of the Max Planck Institute for Plasma Physics, near Munich, has not yet made its findings public, and subscriber states' delegations are unwilling to reveal their negotiating positions on Horizon 2000 's budget. But the British delegation is unlikely to agree funding for specific space science projects until problems raised in the Pinkau report have been debated in full.

The Hipparcos astronomy satellite is one project caught up in ESA's continuing budgetary arguments. Following its failure to reach a geostationary orbit after launch (see Nature 340, 491; 1989), Hipparcos now communicates with three ground stations, rather than one. This has increased costs so that Hipparcos's original budget will run out in July.

Project scientist Michael Perryman says that a "silent success" has followed the mission's well publicized early difficulties, and Hipparcos is expected to have a further two or three years' life. The satellite will then collect most of the star-mapping data orginally hoped for, but this will need an extra 26 million AU (accounting units; $1 \mathrm{AU}=£(0 \cdot 67)$.

ESA's Science Programme Committee discussed Hipparcos's funding last week. Peter Smith, from the British National Space Centre (BNSC), says opinion was "fairly evenly divided" on whether to agree funding for Hipparcos in advance of the Pinkau report. But the British view prevailed, and a final agreement may now have to wait until June.

Smith says that Hipparcos will almost certainly get the necessary funding. The uncertainty is where the money will come from. The Horizon 2000 budget cannot easily accommodate unforeseen expenditure without cutting back, so ESA may wish to ask subscriber states for more money. Britain "would find it extremely difficult" to produce an extra Hipparcos contribution, Smith says, and might not be alone in this.

Britain's problems with space science funding stem, in part, from the absence of a separately funded national space agency. BNSC has only a coordinating role, and space science is funded from the Science and Engineering Research Council's budget.

Contributions to ESA's science programmes must compete with unrelated research areas, in addition to Britain's space science efforts outside of ESA. British space scientists are keen to collaborate with the US National Aeronautics and Space Administration on ultraviolet astronomy projects, where ESA has no future plans.

Peter Aldhous 